FACULTY OF ECONOMICS AND APPLIED ECONOMIC SCIENCES

CENTER FOR ECONOMIC STUDIES

ENERGY, TRANSPORT \& ENVIRONMENT

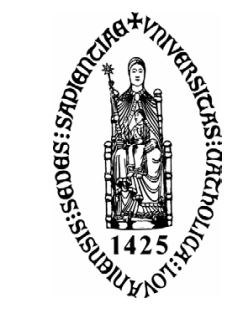

KATHOLIEKE UNIVERSITEIT LEUVEN

WORKING PAPER SERIES

$n^{\circ}$ 2005-04

\title{
TOWARDS BETTER TRANSPORT PRICING AND TAXATION IN BELGIUM
}

\section{Mayeres (Federal Planning Bureau, Brussels)} S. Proost (K.U.Leuven - CES ; UCL - CORE )

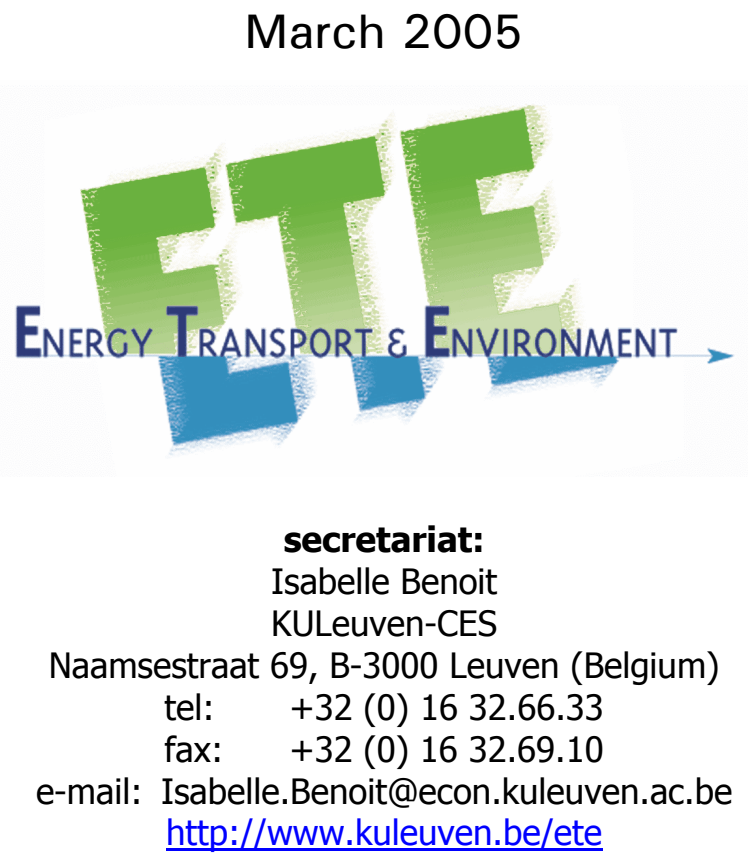




\title{
TOWARDS BETTER TRANSPORT PRICING AND TAXATION IN BELGIUM ${ }^{1}$
}

Inge Mayeres

Stef Proost ${ }^{2}$

Center for Economic Studies

K.U.Leuven

September 2004

\begin{abstract}
Starting from the fundamental principles of transport pricing the paper discusses the relative merits of a number of policy measures. It is argued that in the short to medium run the discouragement of the purchase of new diesel cars is the most important environmental measure that can be taken. A further increase in the fuel efficiency is no priority. In the same time frame parking charges and a cordon toll around major cities have an important role to play, while subsidies to public transport are justified only if a number of conditions are met. A toll on trucks is mainly an interesting way to make transit traffic pay taxes, but could be less useful to control the congestion levels. In the long run prices should be based on marginal social costs. Such pricing measures should be accompanied by a well-directed use of the revenues to correct for the effects on the poorest income groups.
\end{abstract}

Keywords - Transport Pricing, transport taxes, transport externalities

\section{Introduction}

Transport pricing continuously receives a lot of attention in the political debate. The transport sector is one of the sectors in which government intervention is required because the normal functioning of the market creates negative side effects. However, in the general interest of society, one should refrain from pursuing policies that are counterproductive, ineffective and/or too expensive. The aim of this paper is to contribute to the scientific and political debate by summarising recent research on transport pricing.

Our paper first formulates the fundamental principles. Next, we discuss the pros and cons of a number of policy measures that can be taken either in the short to medium run or in the long run. For the short to medium run we consider the following measures: the taxation of cars in function of their environmental damage, parking charges, public transport fares, a cordon toll around cities and a kilometre charge on trucks. For the long run we argue for the introduction of a more sophisticated toll and discuss its effects on tax revenue and on the income distribution. We also analyse whether the toll revenues should be used for financing investments.

\footnotetext{
${ }^{1}$ Published in journal "Reflets et Perspectives de la vie economique",2004,Vol XLIII,N4, pp23-24

${ }^{2}$ Corresponding author: Stef Proost, CES, Naamsestraat 69, 3000 Leuven, Belgium, E-mail: Stef.Proost@econ.kuleuven.ac.be.
} 
From the recent research projects we distil propositions for an improved transport pricing policy in Belgium. Propositions are concise statements that are valid only under certain conditions. In this text we mainly provide intuition for the propositions. The scientific underpinning can be found in the articles that we refer to.

\section{Basic principles for sound transport pricing policies}

\subsection{The fundamental rule}

From an economic point of view it is not rational to consume a good or service if one is willing to pay less than the marginal social cost of providing that good or service. The reason is simple: when a consumer values a good or service less than its cost for society, it is better not to consume the good or service. This is the case for all goods and services, including transport. The argument holds for public and private transport, and for freight and passenger transport.

\section{Proposition 1:}

Each transport activity that does not bear the extra costs it causes to society, should be curbed.

Applying this simple rule is not that straightforward. First of all, it requires policy makers to have a good idea of the extra costs caused by the transport activity. Economists use the term "marginal social costs" to refer to these extra costs to society. In the case of a car trip the marginal social costs consist of the following components (Table 1): the resource cost (or cost before taxes) of the car trip, the time and accident costs of the car user, the environmental costs, the accident costs caused to the other transport users and to society in general, and the extra time costs for the other road users. The resource cost of a car trip consists, among others, of the car costs, the fuel costs, the parking costs, the maintenance costs and the road damage costs.

Table 1: When is the demand for car trips rational?

\begin{tabular}{|c|c|}
\hline $\begin{array}{c}\text { User cost } \\
= \\
\text { marginal benefit for the car user }\end{array}$ & Marginal social cost \\
\hline $\begin{array}{l}\text { - cost of car trip before taxes (car, fuel, } \\
\text { maintenance, parking, ...) } \\
\text { - Own time costs } \\
\text { - Taxes (car, fuel,...) and charges } \\
\text { - Own accident costs }+ \text { insurance premia } \\
\text { for accident costs caused to others }\end{array}$ & $\begin{array}{l}\text { - cost of car trip before taxes (car, fuel, } \\
\text { maintenance, social cost of parking, road } \\
\text { damage costs, ...) } \\
\text { - Own time costs } \\
\text { - Environmental costs } \\
\text { - Own accident costs }+ \text { extra accident } \\
\text { costs caused to others } \\
\text { - Extra time costs caused to others }\end{array}$ \\
\hline
\end{tabular}


Whether the price that car users are willing to pay is at least as high as the marginal social costs of the car trip, depends on the price and tax structure. Car users pay part of the resource costs of their trips and bear their own time and accident costs. They also pay taxes and insurance premia for the accident costs caused to others.

Therefore, one has to determine whether the car and fuel taxes, the other charges and the insurance premia are equal to the uncovered resource costs, the environmental costs and the time and accident costs caused to others. If this is not the case, the taxes and charges need to be reformed. This is illustrated in Figure 1 for the car transport market. To simplify things, the figure assumes that the car users completely pay for the resource costs. Moreover, insurance premia are not taken into consideration. The optimal demand for car transport $\left(X_{o p t}\right)$ corresponds with the intersection between the demand curve and the marginal social cost curve. In this point the price that car users are willing to pay equals the marginal social costs. The optimal tax that is indicated on the figure makes sure that this point is reached. Without this tax transport demand would equal $X_{n o} \operatorname{tax}$. At this level of transport demand the price that car users are willing to pay is lower than the marginal social cost. People therefore use their car too much.

Figure 1: The fundamental rule

\section{Generalised price}

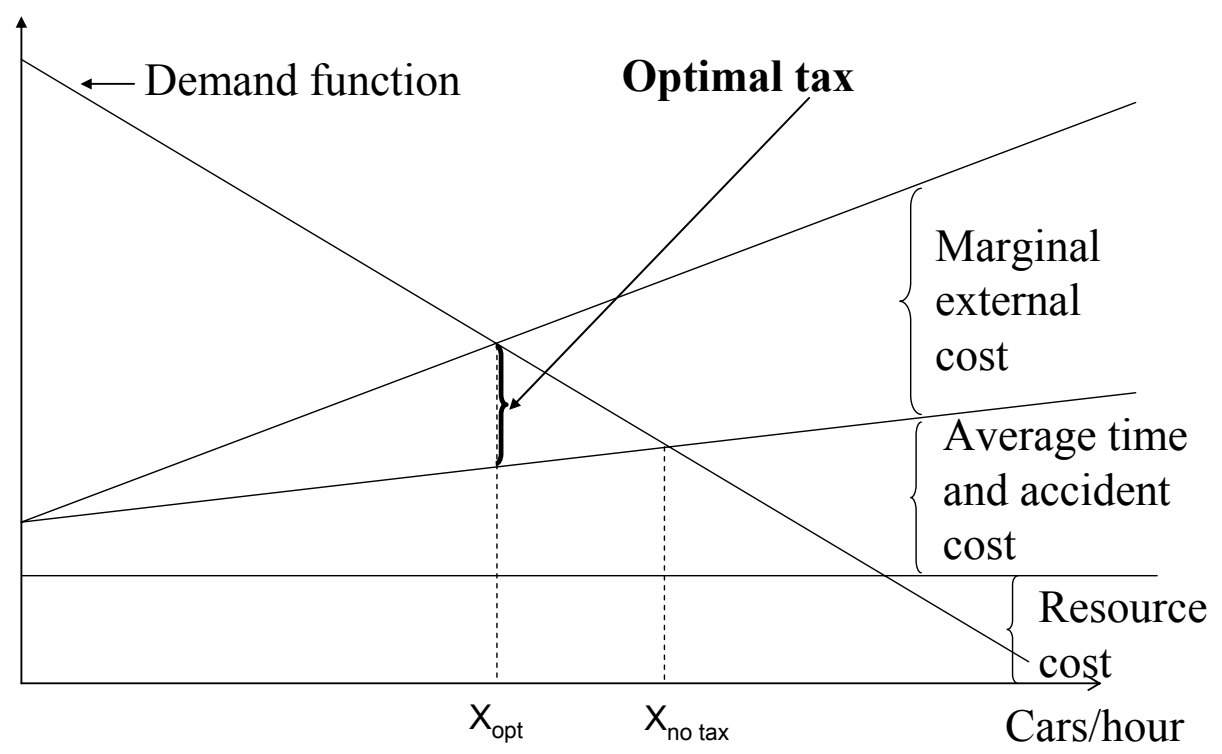

This fundamental rule should be satisfied not only for an average car trip, but for each type of car trip: for clean and dirty cars, in the peak and the off-peak period, for careful and dangerous drivers, in urban and non urban areas. Furthermore, the rule should also be satisfied for the other transport modes. 
It is important to note that the fundamental rule assigns the responsibility for the choice of the transport mode and the number of kilometres to the transport users, since they know best what is good for themselves. This is an important characteristic of the economic approach and distinguishes it from regulation. The role of the government is to make sure that the prices reflect the marginal social costs. The power and efficiency of this approach is often underestimated. Apparently, politicians mainly believe in the effect of price reductions, rather than price increases. Of course, price instruments are not the only measures that are worthwhile. Certainly in the case of transport safety, regulatory measures are often advisable.

It is clear that with the current flat structure of transport prices the demand for transport is not rational in all circumstances. This is the reason why economists argue that there are inefficiencies: the prices are not equal to the marginal social costs, causing the demand for transport non-optimal. The next question that comes to mind is: how important is this problem? How large are the pricing inefficiencies?

\subsection{How large are the pricing inefficiencies?}

The TRENEN-II STRAN project ${ }^{3}$ is one of the projects that has examined current transport pricing practices in Europe. Figure 2 gives an idea of the pricing inefficiencies in Brussels in 2005 for different transport markets under a business-asusual scenario.

Figure 2: $\quad$ Are the current prices correct? - Brussels 2005

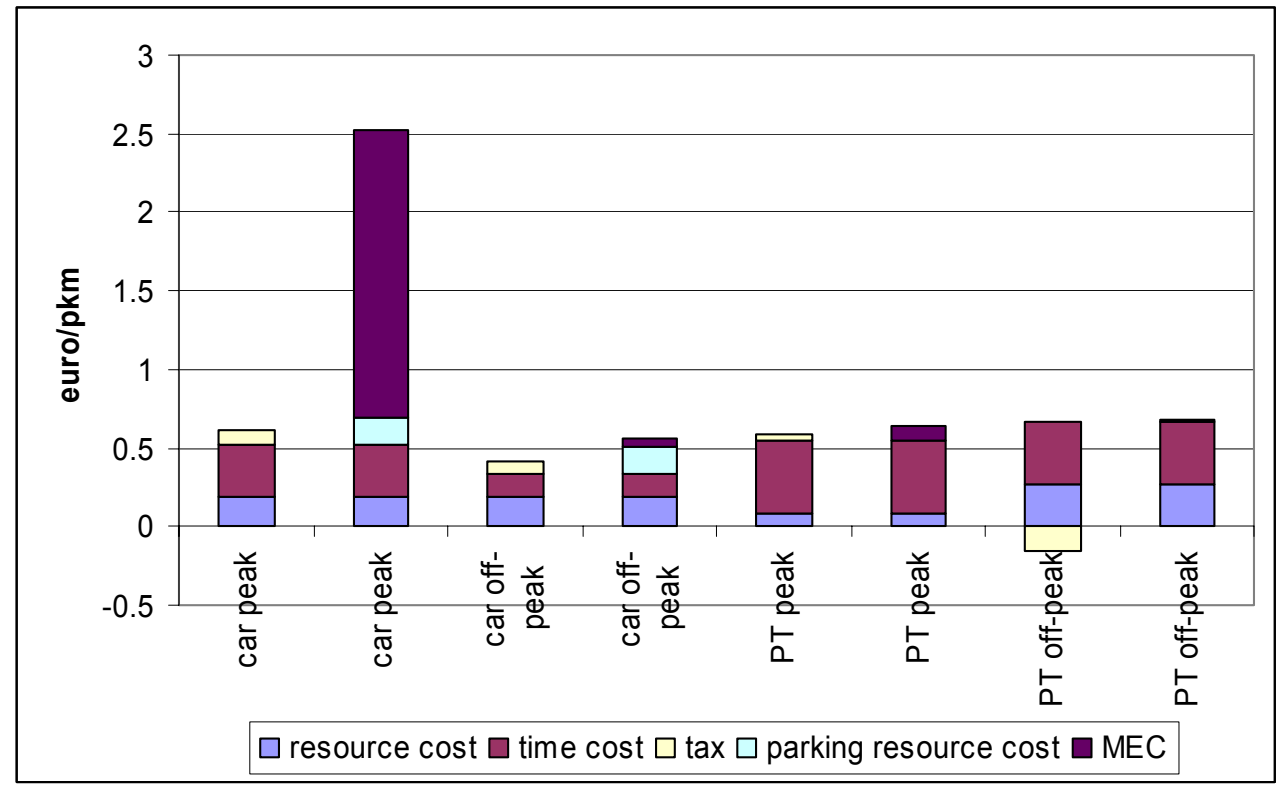

Car = small gasoline car, 1 occupant, resident of Brussels, no parking charge; PT = public transport (bus, tram, metro); MEC = marginal external costs; $\mathrm{pkm}=$ passenger kilometre

Source:De Borger \& Proost (2001)

\footnotetext{
${ }^{3}$ The TRENEN-II STRAN project was financed by the fourth framework programme of the European Commission. The results are summarised in Proost et al. (2002). A more detailed discusssion of the methodology and the results is presented in De Borger \& Proost (2001).
} 
For car transport Figure 2 considers the case of a small gasoline car with one occupant who is a resident of Brussels and who does not pay a parking charge. For each transport mode the left column presents the generalised price $(=$ money price + time cost) per passenger kilometre ( $\mathrm{pkm})$, while the right column presents the marginal social costs. During the peak period there is a large divergence between the generalised price and the marginal social costs, which indicates that peak transport demand is not rational. The situation is less dramatic during the off-peak period. It is important to note that also the demand for public transport is irrational since the public transport prices are lower than the marginal social costs. 


\section{Proposition 2:}

In the peak period the price of private car transport and public transport is too low in urban areas.

Figures 3 and 4 present the situation for interregional transport in Belgium in 2005 under a business-as-usual scenario. Figure 3 refers to passenger transport, while Figure 4 concerns freight transport. The information for road transport relates to highways. For each transport mode a comparison is made between the taxes per passenger or tonne kilometre (left column) and the marginal external costs (right column). Also in this case the differences are more pronounced during the peak period. In almost all cases the taxes are lower than the marginal external costs. The marginal external costs differ strongly between the transport modes. The variable costs of public transport are also subsidised.

\section{Figure 3: Are the current prices correct? - Belgium 2005 - passenger} transport

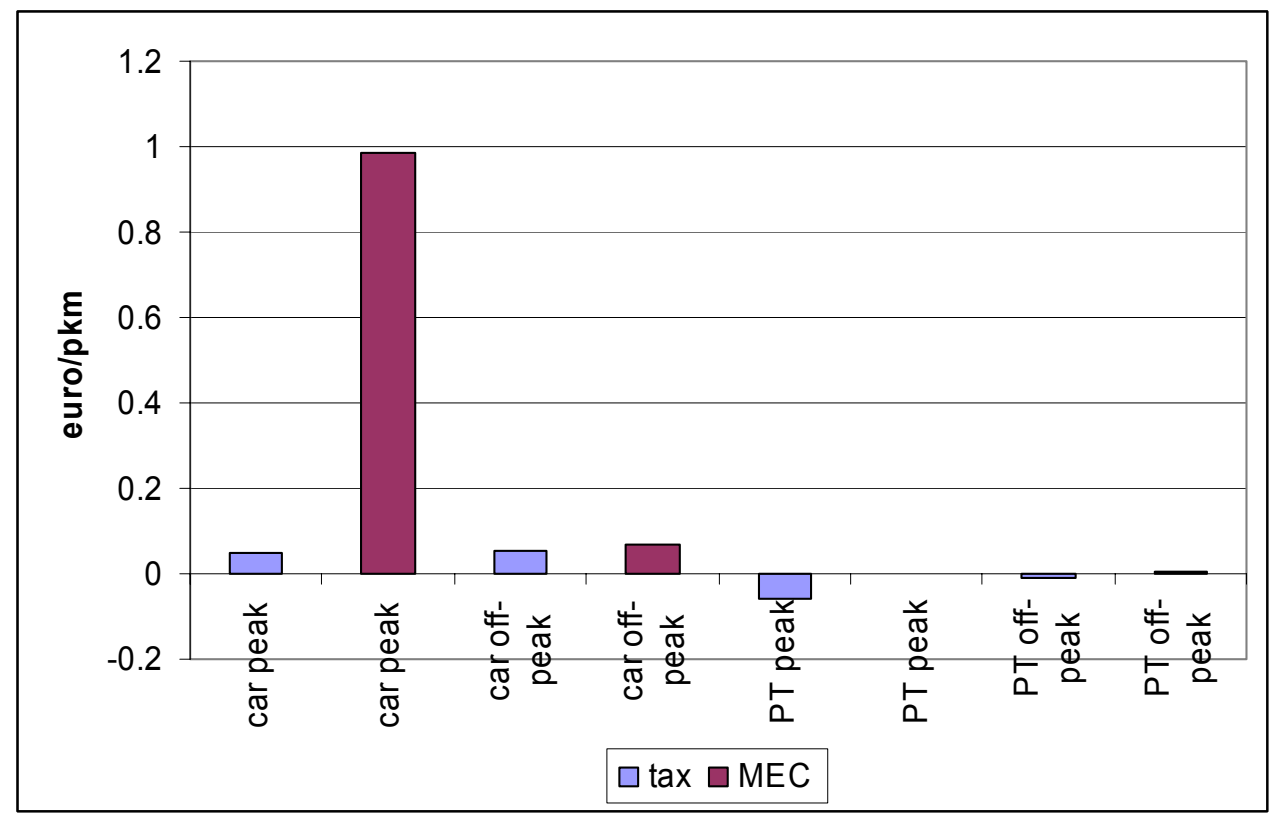

Car $=$ small diesel car, 1 occupant, highway; $\mathrm{PT}=$ train; $\mathrm{MEC}=$ marginal external cost; $\mathrm{pkm}=$ passenger kilometre

Source: De Borger \& Proost (2001) 
Figure 4: $\quad$ Are the current prices correct? - Belgium 2005 - freight transport

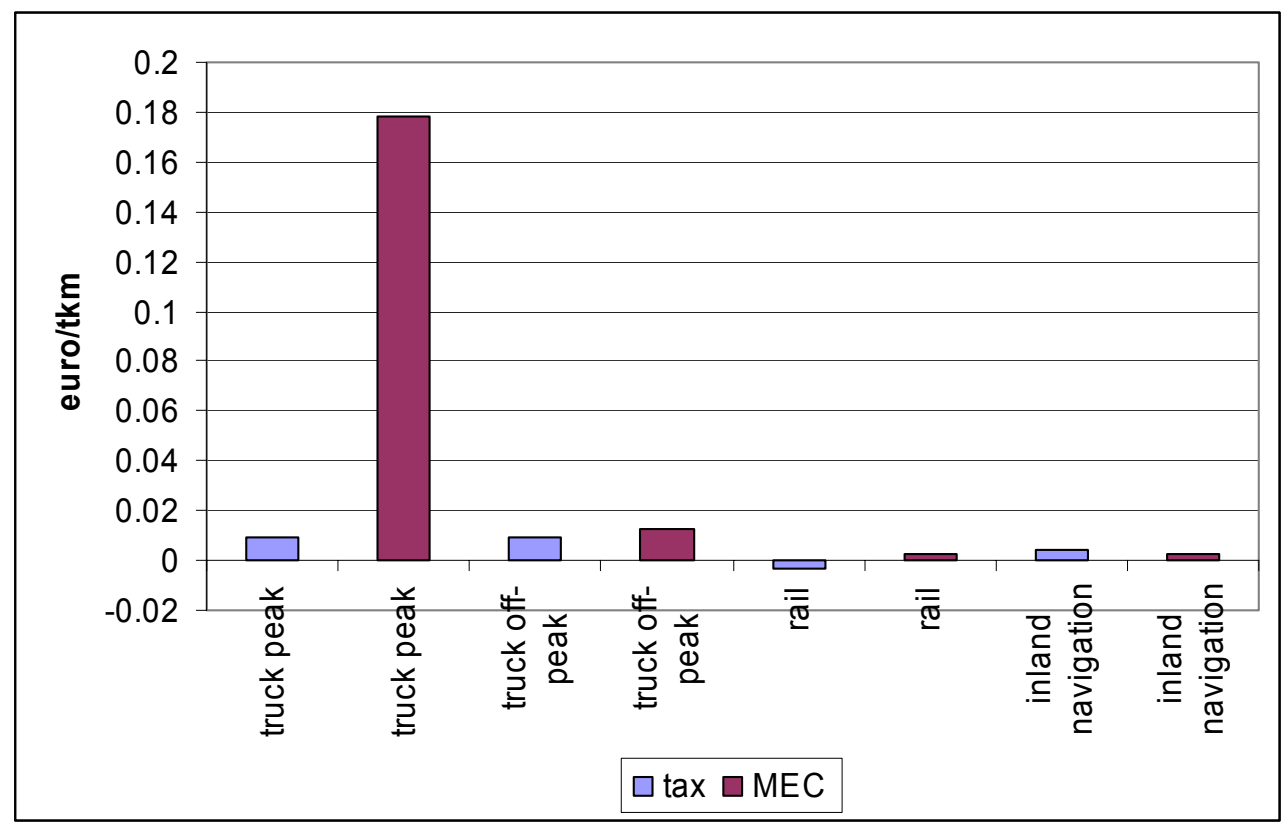

- The figures for trucks relate to highways

- MEC = marginal external costs; $\mathrm{km}=$ tonne kilometre

Source: De Borger \& Proost (2001)

The TRENEN-II STRAN project presents a diagnosis, but also indicates how the current taxes should be changed in order to solve the problem. In the next section we discuss the form these price reform should ideally take, when the government can use perfect policy instruments. This case should mainly be considered as a benchmark with which the other policy options can be compared. Afterwards, we evaluate a number of concrete policies that can be pursued in the short and the long run.

\subsection{The ideal case}

Table 2 gives an indication of the change in money prices and taxes that should ideally take place in Brussels and Belgium if the government could make use of perfect instruments ${ }^{4}$. Since the results were obtained with a very aggregated model, the table only gives an indication. However, it does show that both for Brussels and for Belgium a strong increase in taxes is required for car and truck transport in the peak period. In the off-peak period taxes should also be raised, but less so. For public transport the existing subsidies per passenger $\mathrm{km}$ should be abolished and replaced by taxes. 5 . The table also present the effect of these measures on the marginal external costs.

\footnotetext{
${ }^{4}$ The exercise for Brussels takes into account the existence of distortionary taxes in the rest of the economy, while the exercise for Belgium does not. Therefore, the results for the two case studies cannot be simply compared with each other.

${ }^{5}$ The subsidy of the difference between the average and the marginal resource cost is maintained.
} 
Proposition 3:

Marginal social cost pricing implies that in the peak period the taxes on car and truck transport should substantially be increased. In the off-peak period the taxes should also rise, but less so. For public transport the existing subsidies that are related to the variable costs should be abolished and replaced by taxes.

Table 2: $\quad$ The change in prices, taxes and marginal external costs in Brussels and Belgium with optimal policy

\begin{tabular}{|c|c|c|c|c|c|c|}
\hline & \multicolumn{3}{|c|}{ Brussels } & \multicolumn{3}{|c|}{ Belgium } \\
\hline & \multicolumn{3}{|c|}{$\begin{array}{l}\text { Percentage change w.r.t. the } \\
\text { reference equilibrium }\end{array}$} & \multicolumn{3}{|c|}{$\begin{array}{l}\text { Percentage change w.r.t. the } \\
\text { reference equilibrium }\end{array}$} \\
\hline & $\begin{array}{l}\text { Money } \\
\text { cost }\end{array}$ & Tax & MEC & $\begin{array}{l}\text { Money } \\
\text { cost }\end{array}$ & Tax & MEC \\
\hline \multicolumn{7}{|l|}{ Passenger transport } \\
\hline Car - peak & $+219 \%$ & $+499 \%$ & $-78 \%$ & $+159 \%$ & $+600 \%$ & $-64 \%$ \\
\hline Car- off-peak & $+101 \%$ & $+127 \%$ & $0 \%$ & $+7 \%$ & $+25 \%$ & $-3 \%$ \\
\hline PT peak & $+33 \%$ & $+105 \%$ & $-78 \%$ & $+135 \%$ & $-103 \%{ }^{\mathrm{a}}$ & $0 \%$ \\
\hline PT off-peak & $+213 \%$ & $-169 \%{ }^{\mathrm{a}}$ & $+14 \%$ & $+24 \%$ & $-138 \%{ }^{a}$ & $0 \%$ \\
\hline \multicolumn{7}{|l|}{ Freight transport } \\
\hline Road peak & & & & $+98 \%$ & $+644 \%$ & $-62 \%$ \\
\hline Road off-peak & & & & $+7 \%$ & $+44 \%$ & $0 \%$ \\
\hline Rail & & & & $+15 \%$ & $-200 \%{ }^{a}$ & $0 \%$ \\
\hline Inland navigation & & & & $0 \%$ & $0 \%$ & $33 \%$ \\
\hline
\end{tabular}

- For Brussels: $\mathrm{Car}=$ small gasoline car, resident of Brussels, no parking charge in the reference equilibrium

- For Belgium: Car = small diesel car

- The results for road transport in Belgium refer to highways

${ }^{\mathrm{a}}$ These cases correspond with the replacement of subsidies by taxes

Source: De Borger \& Proost (2001)

Applying these theoretical recommendations in practice is not easy. First of all, one needs to determine the level of the marginal external costs. Measuring the marginal external costs can involve error margins, but is possible in principle ${ }^{6}$. Even an imprecise estimate of the marginal external costs can form an important basis for improving current policies. It does not only teach use that the price of urban car transport is substantially too low during the peak period, but also that diesel cars cause more environmental damage than gasoline cars and that urban buses in the off-peak period cause high marginal costs in the form of air pollution and noise.

\footnotetext{
${ }^{6}$ The UNITE project (fifth framework programme - Transport RTD programme of the European Commission) has made a survey of the existing estimates of the marginal external costs and has developed further the methodology for determining the marginal external costs. (www.its.leeds.ac.uk/projects/unite/index.html)
} 
Secondly, the right policy instrument needs to be chosen to correct for the inefficiencies. For example, the taxes on the purchase and ownership of cars can easily be differentiated according to the environmental characteristics of the vehicles. However, it is more difficult to differentiate taxes in function of time and place of travel. Fuel taxes do not allow for this, and therefore are not an appropriate instrument to correct for congestion. More sophisticated instruments are required which cannot be implemented easily in the short run. However, this does not mean that nothing can be done in the short run. In the next sections we evaluate the performance of a number of measures that can be implemented in the short to medium run. Afterwards, we present instruments that are more suited for the longer run.

\section{Short to medium term measures}

We consider five policy measures that can be implemented in the relatively short run. The implementation of the first three measures is very simple. It concerns:

- a correct taxation of gasoline and diesel cars;

- better parking charges;

- a change in public transport fares.

In addition, we consider two measures of which the implementation is more complicated, but that can also be taken in the medium run, as is evident from existing and planned schedules in a number of European countries ${ }^{7}$. They consist of:

- the introduction of a cordon toll around major cities;

- the introduction of a kilometre charge on trucks.

\subsection{A correct taxation of gasoline and diesel cars}

In Belgium in 2002 the share of diesel cars in the car stock was $43.4 \%$. In the same year more than $64 \%$ of the newly registered cars was a diesel car. EU trends are similar. It is expected that the share of diesel cars will increase even further in the future. However, diesel cars are more polluting than gasoline cars. They also raise less revenue than gasoline cars (because diesel cars are more fuel efficient). This situation has partly arisen because the tax authorities did not take into account the technological developments for diesel cars and new scientific analyses that point to the environmental damage caused by particulate matter.

Proposition 4:

The discouragement of the purchase of new diesel cars is the most important environmental measure that can be taken now in the transport sector.

\footnotetext{
${ }^{7}$ Another measure that should clearly be considered is the tax treatment of company cars. This is less straightforward than it seems at first when company cars are seen as part of the wage and when it is recognised that a tax exemption for company cars influences the effective employment rate. This is analysed in ongoing research by De Borger \& Proost.
} 
The taxation of diesel and gasoline cars is constrained by a number of factors. First of all, in the short run it is difficult to tax car use directly, so that one has to tax the inputs of car use instead. Therefore, one has to resort to taxes on the purchase or ownership of cars and to fuel taxes. Of these two types of instruments the fuel taxes are probably the most appropriate to correct for the external costs, but they also have a number of disadvantages. As was mentioned before, fuel taxes cannot be differentiated according to the time and location of travel, nor can they be made dependent on the emission technology of the vehicle. Fuel taxes will also lead to vehicles which are too fuel efficient from a social point of view. Fixed taxes have the advantage that they can be made dependent on the emission characteristics of the vehicles.

Secondly, it is difficult for the government to observe the purpose for which cars and car fuel are used. Diesel is used both by cars and trucks. This points to an important role for fixed taxes that can be differentiated between cars and trucks, whereas it is less easy to realise this for fuel taxes. However, it is also difficult to make a distinction between car ownership and use for private and business purposes. This puts constraints on the contribution of taxes on car ownership and car use to the revenue raising objective.

Finally, the role of fuel taxes is complicated by the possibility of fuel tourism. In a small country with a lot of transit traffic, such as Belgium, policy makers may be tempted to set the fuel tax somewhat lower than in neighbouring countries in order to generate extra income. Higher fuel taxes are also less attractive because Belgian residents and companies can buy their fuel abroad.

If, because of these reasons, one does not wish to change the current fuel taxes, the large share of diesel cars can be corrected by raising the tax on the purchase and ownership of diesel cars relative to gasoline cars ${ }^{8}$.

Proposition 5:

A further reduction in the fuel efficiency per kilometre is not a priority.

The current excises mainly intend to raise revenue, to limit the volume of peak transport and to limit the emission of traditional pollutants. Vehicles that consume less fuel contribute to the achievement of the Kyoto objective for $\mathrm{CO}_{2}$ emissions, but do so at a cost that is much higher than the cost of emission reduction in the rest of the economy. A litre of diesel that is used by cars costs approximately 0.7 euro, while a litre of diesel that is used in the residential sector costs 0.25 euro. Both types of diesel emit the same amount of carbon. However, it is cheaper to save energy in the residential sector. Indeed, each sector only has an interest in investing in more efficient technologies as long as the cost of these technologies per litre of fuel saved is smaller than or equal to the price of a litre of fuel. The existing fuel prices imply that

\footnotetext{
${ }^{8}$ see: Mayeres \& Proost (2001a), De Borger \& Mayeres (2004)
} 
up to now the potential saving in energy costs were much higher in the transport sector than elsewhere, and that the transport sector has already gone much further in energy saving than other sectors. Hence, it will cost much more than in other sectors to reduce the energy use even further in the transport sector. A further decrease in the fuel consumption per kilometre by cars therefore is not a priority for policy (Proost \& Van Dender, 2001).

\subsection{Parking charges}

Parking charges can make an important contribution to solving urban transport problems. One of the causes of urban transport problems is that not all car users have to pay for parking at their destination, either because their employer or shop offers them free parking, or because they can park their car for free on the road. Because the resource costs of these parking spaces obviously is not equal to zero, an inefficiency arises. Exercises with the TRENEN model for Brussels show that one can obtain $30 \%$ of the welfare gain of the optimal policy by letting everyone pay the resource cost of parking (see Table 3). As regards the on-street parking fares, the parking fares of private parking lots are a good indication (Calthrop \& Proost, 2004). However, the parking charges cannot be differentiated sufficiently between the peak and the offpeak period, which explains why one can obtain only $30 \%$ of the maximal welfare gain. It should be noted that the performance of the measure can be expected to depend on local circumstances.

\section{Proposition 6:}

Parking measures have an important role to play in transport policy in the short run. The parking charges of private parking lots are a good indication for the on-street parking charges.

Levying higher parking charges should be accompanied by good enforcement policies. Table 3 does not yet take into account the enforcement costs. Since the revenues from parking charges in principle benefit local government, it has an incentive to ensure a good enforcement policy.

Table 3: $\quad$ The relative efficiency of a selection of policy instruments Brussels 2005

\begin{tabular}{lc}
\hline Policy instrument & Relative efficiency w.r.t. optimal policy \\
\hline Current situation & $0 \%$ \\
Better public transport fares & $5-10 \%$ \\
Better parking charges & $30 \%$ \\
Cordon toll & $52 \%$ \\
Optimal policy & $100 \%$ \\
\hline
\end{tabular}

Source: Proost \& Van Dender (2001) 


\subsection{Public transport fares}

Higher subsidies to public transport are often considered as an alternative measure if, for one reason or another, the price of private transport cannot be set equal to marginal social costs. However, the desirability of higher public transport subsidies depends on a number of crucial conditions. Before going into these conditions, we first discuss the subsidies and the marginal social costs we focus on. We do this for the case of rail transport.

We do not consider the subsidies that are meant to cover the fixed costs of providing the tracks (approximately $50 \%$ to $60 \%$ of total railway costs). We only consider those subsidies that allow to sell public transport services at a price below the marginal cost. As in the case of road transport, there are large differences in the marginal cost of a public transport service in the peak and the off-peak period. For example, the marginal cost of a rail trip between Leuven and Brussels in second class could be 6 euro (the price of a first class ticket) while the marginal cost in the off-peak period could be only 1 to 2 euro (the current price for season-tickets in second class).

Proposition 7:

Public transport fares should be differentiated according to time and location of travel. Subsidising public transport during the peak period is justified only if a number of conditions are met.

Subsidising public transport during the peak period is justified only if the following conditions are met:

- First of all, it must be impossible to charge a correct price to private transport. If it is possible to increase the price of private transport, it becomes less attractive to maintain or increase the public transport subsidies. This is the reason why in the long run both the prices of private and public transport need to be increased in the peak period (see Table 2).

- Secondly, it only makes sense to make public transport cheaper, if this encourages a sufficiently large number of people to switch from car transport to public transport on those links and those times of travel where there is a lot of congestion. Subsidies are mainly justified on links in the direction of the big cities and during the peak period and only to the extent that car users switch from car use to public transport.

- Thirdly, the own price elasticity of public transport should be limited, otherwise it becomes a very expensive measure.

- Fourthly, the subsidy should be differentiated according to trip motive, where the commuting motive should be associated with lower prices since this increases labour supply (Van Dender, 2003). 


\subsection{A cordon toll around major cities}

Several cities consider the introduction of a cordon toll. In Belgium this could be worthwhile for Brussels and Antwerp. With a simple aggregated model we have analysed the efficiency of a cordon toll for Brussels, where the toll depends on the time at which one travels. We found that a cordon toll around Brussels leads to a positive result, but that it is less efficient than more sophisticated forms of road pricing. The reason is than a cordon toll mainly limits inbound traffic and that traffic that remains inside the cordon partly increases when inbound traffic falls. In Table 3 we therefore see a relative efficiency of $52 \%$ of the cordon toll in comparison with the optimal policy. The cordon toll therefore needs to be complemented by other instruments, such as higher parking charges, to limit traffic within the cordon.

\section{Proposition 8:}

A time-dependent cordon toll around major cities, contributes to a reduction in congestion, but needs to be complemented by measures such as higher parking charges.

The implementation of a cordon toll will imply conflicts of interest between different regions (Brussels) or between the city (Antwerp) and the region. With the same simple model we have illustrated ${ }^{9}$ the efficiency loss that would arise when a local government only sets its transport policy for the benefit of its own citizens. We considered the case where the city of Brussels can set the parking charges and keep the revenues from these charges, whereas the federal government can determine the level of a cordon toll around Brussels. In this setting the Brussels government will raise as much revenue as possible from parking charges since this is a way of taxing non-residents. The federal government will then charge a relatively low cordon toll since transport demand is already reduced by the high parking charges in Brussels. A surprising result of this game with conflicting interests is that the final outcome is not that inefficient. It results in a shift of taxation to the commuters, but from a transport economic point of view the result is $90 \%$ as efficient as when one government level perfectly controls the two policy instruments.

\section{Proposition 9:}

The distribution of pricing competences between the regions and the federal government does not necessarily lead to large inefficiencies.

\footnotetext{
${ }^{9}$ See De Palma et al. (2003)
} 
Of course, other coordination problems can arise between the regions and the cities which could lead to larger efficiency losses. Therefore, consultation is important.

\subsection{A kilometre charge on trucks}

Belgium could have an interest in introducing a kilometre charge on trucks since it is a transit country. Many foreign trucks drive through Belgium. They do not pay fuel taxes in Belgium, but cause costs: they increase congestion and accident risks, they contribute to air pollution and cause road damage.

The existing Eurovignette directive, that needs replacement, only applies to highways. The directive only covers infrastructure costs and not the external costs. The price of the Eurovignette does not depend on the number of kilometres that is driven. In Belgium its price is however related to the number of axles and the environmental characteristics of the vehicle.

Some European countries have already introduced a toll on truck transport that is related to the number of kilometres driven, besides other characteristics of the vehicle (e.g., Switzerland has introduced a toll on the complete network and Austria charges a toll on highways and expressways), or is thinking of introducing such a toll (e.g., Germany and the United Kingdom). The European Union is developing a new legislative framework for this (proposal for revision of the Eurovignette directive) and has to ensure that the technological side develops in a coordinated way (EU proposal of directive of April 2003).

In principle each country can determine the toll level itself. For the time being the toll must still be based on the infrastructure costs of the lasts years, but in the future the toll can also be differentiated spatially and in time. In Belgium the implementation in the regions must be coordinated by the federal government.

The new European proposal says that the toll revenues need to be used within the transport sector. From an economic point of view this is not the best option. It is preferable that the revenues are added to the other tax incomes and that the money is used where it can achieve the highest benefits. This is not necessarily in the transport sector.

Taxing freight transport only is a partial solution if the price of passenger transport is not changed. However, an exercise for the United Kingdom ${ }^{10}$ shows that a tax on freight transport can increase welfare under certain conditions, even if the taxes on passenger transport remain substantially too low. The study also provides a better insight in the characteristics of a tax on freight transport:

- The higher the indirect cross-price effects of the tax on freight transport on passenger transport (via the price of the transported commodities and the level of congestion), the lower the optimal level of the tax on freight transport. If a

\footnotetext{
${ }^{10}$ see Calthrop et al. (2003). The study examines a more general tax than the one that is proposed by the EU. More specifically, it takes into account all external effects. Furthermore, the study assumes that the tax income is used to reduce labour taxes.
} 
higher tax on freight transport substantially increases passenger transport, this aggravates the problems on the market for passenger transport.

- The benefit of a given tax on freight transport increases as the tax on passenger transport is higher. This reflects the fact that the existing taxes on passenger transport are not yet correct.

- The higher the tax on passenger transport, the lower the optimal tax on freight transport. A higher tax on passenger transport leads to lower marginal external costs of freight transport and therefore to a lower tax on freight transport. This result has important policy implications, if one wants to introduce road pricing piecewise, first for freight transport and next for both freight and passenger transport.

This means that the toll on freight transport can be interesting when it generates extra income from transit traffic and when the revenue is well spent, for example to reduce the social security taxes. But, one shouldn't expect too much from the toll of trucks in terms of congestion reduction because latent car demand will take part of the freed road space.

Proposition 10:

A toll on trucks mainly is an interesting way of making transit traffic pay taxes. It could have only a small effect on the congestion levels.

Continuing our reasoning, we must also question the subsidies for inland navigation and railways that are intended to mitigate the congestion problem by luring freight transport off the road. When the freed road space is taken by additional cars, the subsidies are not a very efficient way of reducing congestion and the total cost-benefit balance could well be negative.

Proposition 11:

As long as road traffic does not pay the correct price, infrastructure measures for rail and inland navigation are not very efficient.

\section{Longer term solutions}

In the longer run more sophisticated solutions are possible than in the short run. New technological developments offer the possibility of introducing an electronic toll, where the toll can be differentiated in function of the time of travel and the road type. This allows to charge a price that corresponds more closely to the marginal social costs. In the next paragraphs we briefly discuss the possibilities of such a system. We also go into the impact on government revenue and the use of these revenues. We stress the link between the use of the revenues and the effects on the different income groups. Finally, we discuss the link between pricing and investment policy. 


\subsection{Marginal social cost pricing and the impacts on government revenue}

Table 4 summarises some effects of marginal social cost pricing for five countries. The results are based on an ECMT study with the TRENEN model. In all cases considered marginal social cost pricing leads to a welfare gain. There also is a substantial increase in transport tax revenues. 
Table 4 : $\quad$ Expected effects of marginal social cost pricing

\begin{tabular}{lccccc}
\hline & $\begin{array}{c}\text { Great- } \\
\text { Britain }\end{array}$ & France & Germany & $\begin{array}{c}\text { The } \\
\text { Netherlands }\end{array}$ & Finland \\
\hline $\begin{array}{l}\text { Welfare gain } \\
(10 \text { ) euro/year) }\end{array}$ & 17 & 10 & 6 & 2 & 1 \\
Tax revenue & $+65 \%$ & $+56 \%$ & $+64 \%$ & $+31 \%$ & $-20 \%$ \\
$\begin{array}{l}\text { Air pollution costs } \\
\text { Congestion }\end{array}$ & $-54 \%$ & $-50 \%$ & $-35 \%$ & $-31 \%$ & $-42 \%$ \\
$\begin{array}{l}\text { (change in speed } \\
\text { in the peak period) }\end{array}$ & $+10 \%$ & $+9 \%$ & $+13 \%$ & $+12 \%$ & - \\
\hline Source: ECMT 2003 & & & & & \\
\hline
\end{tabular}

These studies show that - on average, for all modes taken together and for a given capacity - marginal social cost pricing will lead to financial surpluses in the transport sector, certainly in urban areas. If one considers the different modes separately, then for some modes surpluses are generated (road, certainly in urban areas). For the other modes the results are mixed.

\section{Proposition 12:}

On average, for all modes together and for a given capacity, marginal social cost pricing leads to financial surpluses in the transport sector, especially in urban areas.

One can wonder to what extent one should strive for a financial balance for all modes. This is a recurring question of the car lobby. A study ${ }^{11}$ has compared marginal social cost pricing with other options that guarantee a break-even for all modes separately. To obtain such a break-even one can choose between several options:

- charging the average financial cost to each mode.

- charging Ramsey prices based on the marginal social costs with a possibility of a mark-up over marginal social costs.

- A two-part tariff, that consists of a fixed component and a variable component that depends on the use. This last option will not be elaborated upon further in this paper, although it can be useful ${ }^{12}$.

Table 5 compares the welfare gain that can be realised with marginal social cost pricing (with budget constraints) to the welfare effects for the two other pricing scenarios that guarantee a break-even situation. The table presents results for a number of areas in Germany and the United Kingdom.

\footnotetext{
${ }^{11}$ Proost \& Van Dender (2004)

12 see, for example, De Borger (2001)
} 
Table 5: $\quad$ Welfare effects of alternative pricing scenarios (2005) (percentage change in generalised income w.r.t. the reference equilibrium)

\begin{tabular}{lccc}
\hline & $\begin{array}{c}\text { Price }=\text { average } \\
\text { financial cost }\end{array}$ & $\begin{array}{c}\text { Price }=\text { Ramsey } \\
\text { price, based on } \\
\text { marginal social cost }\end{array}$ & $\begin{array}{c}\text { Price = marginal } \\
\text { social cost }\end{array}$ \\
\hline Germany & & & \\
Düsseldorf & $-0,8 \%$ & $+0,1 \%$ & $+0,1 \%$ \\
München & $-0,6 \%$ & $+0,1 \%$ & $+0,4 \%$ \\
Münster & $-2,5 \%$ & $-2,2 \%$ & $+2,5 \%$ \\
Westphalen & $-0,2 \%$ & $-0,1 \%$ & $+0,1 \%$ \\
\hline UK & & & $+2,7 \%$ \\
London & $-0,8 \%$ & $+1,3 \%$ & $+0,6 \%$ \\
Southeast Region & $-1,9 \%$ & $+0,2 \%$ & \\
\hline
\end{tabular}

Bron: Proost \& Van Dender (2004)

\section{Proposition 13:}

Imposing a budget constraint for the transport sector as a whole or for the transport modes separately reduces the efficiency gains that can be obtained by means of pricing reforms. Furthermore, the way in which the budget constraint is met has important consequences for the welfare effects.

In all cases considered charging the average financial costs leads to a welfare loss. The reasons for this are as follows:

- If car use is too cheap from a social point of view and this cannot be corrected because of a break-even constraint for the road sector, there is a role for public transport subsidies. However, this is not possible if there is a budget constraint for each transport mode separately. The taxes on each mode then are determined to a large extent by the budget constraint for that mode and not by the prices of the substitute transport modes.

- The revenues of the current transport taxes are higher than what is required by the budget constraints for the transport sector as a whole. Optimal tax theory shows that, if transport demand is relatively price inelastic, it costs relatively little to raise revenue in that sector. The fact that extra tax revenue is currently raised in the transport sector can then be justified.

Ramsey pricing leads to better results than average financial cost pricing. The system also imposes a budget constraint, but allows for a larger differentiation of prices. With Ramsey prices one can obtain $30 \%$ to $90 \%$ of the welfare gain with marginal social cost pricing.

In all cases marginal social cost pricing performs better. This indicates that the revenues that are obtained in this scenario are an important component of its welfare effect. 
However, it should be noted that the importance of budget constraints should not be downplayed. In certain circumstances they can also be useful. They can for example give an important signal to transport operators to produce efficiently.

\subsection{Pricing and investment}

\section{Proposition 14:}

A given infrastructure (roads, railways, canals, harbours) is always used most efficiently when its users pay the marginal social costs.

If the capacity of the infrastructure is very large, then the best price for the use of the infrastructure will equal the marginal operating costs (in the absence of environmental or accident costs). However, if infrastructure capacity is too low, a price needs to be charged such that demand equals the available capacity. Only this way one can ensure that the people who use the infrastructure are those that need it the most. This principle is valid independent of the infrastructure policy that was pursued in the past. It is therefore also worthwhile to improve transport pricing even if the infrastructure capacity is not optimal. Note that a similar principle also holds for private companies that charge a price dependent upon what consumers can bear and where sunk costs are as irrelevant as in the determination of optimal transport prices by the government.

Of course it is advisable that a good investment policy is pursued, but it is not the case an incorrect investment policy would lead to different pricing rules. The pricing rules do not change, even though the price level depends on the available capacity. The prices should be reduced when capacity is expanded.

A study by CE (2002) compares for an urban area the equilibrium with optimal prices and unchanged infrastructure with the equilibrium with optimal prices and optimal investments. The study shows that the prices are not much lower in the second case. Moreover, the total surplus does not differ a lot between the two cases. This is because the expansion of the infrastructure capacity in an urban area is expensive.

Very often it is also argued that one should first increase the capacity of public transport before changing the prices of private transport. This is not necessarily true. In general correct pricing implies much higher prices of road transport in the peak in urban areas and may imply lower prices in more rural areas. For public transport the efficient prices may also increase substantially at certain moments and locations. The net effect on the demand for public transport is unclear and it is not necessarily the case that the capacity of public transport should increase by a lot. This question requires additional research with a network model. 


\subsection{Transport pricing reforms and income distribution}

In order to know the distributive effects of transport pricing reforms, one needs to analyse who gains and who loses. This depends not only on the transport pricing policies but also - and especially - on the way in which one uses the extra revenues generated by these policies, or the way in which one compensates for a reduction on tax revenues ${ }^{13}$.

This means among other things that higher public transport subsidies are not necessarily an efficient way to favour poorer people. Indeed, these subsidies need to be financed. A study for Belgium ${ }^{14}$ shows that higher public transport subsidies reduce welfare of the lower income groups if they are financed by lower social security transfers. But if they are financed by higher labour taxes they entail a redistribution from the richer to the poorer income groups.

Marginal social cost pricing is often attacked for being an asocial measure. Table 6 gives the effects on five different income groups of two pricing measures: average cost and marginal social cost pricing.

Table 6: The effects of transport pricing reforms on five income groups (Belgium 1990)

\begin{tabular}{|l|c|c|c|}
\hline & $\begin{array}{c}\text { Price = average } \\
\text { financial cost } \\
\text { Reduction in tax } \\
\text { revenues } \\
\text { compensated by } \\
\text { higher labour } \\
\text { tax }\end{array}$ & $\begin{array}{c}\text { Price = marginal } \\
\text { social cost } \\
\text { revenues used to } \\
\text { reduce the } \\
\text { labour tax }\end{array}$ & $\begin{array}{c}\text { Price = marginal } \\
\text { social cost } \\
\text { revenues used to } \\
\text { increase the } \\
\text { social security } \\
\text { transfers }\end{array}$ \\
\hline Percentage increase in equivalent income \\
\hline Quintile 1 (poorest quintile) & $-0,78 \%$ & $+0,47 \%$ & $+3,88 \%$ \\
\hline Quintile 2 & $-0,04 \%$ & $+0,03 \%$ & $+2,21 \%$ \\
\hline Quintile 3 & $-0,24 \%$ & $-0,16 \%$ & $+0,75 \%$ \\
\hline Quintile 4 & $-0,20 \%$ & $+0,22 \%$ & $+0.00 \%$ \\
\hline Quintile 5 (richest quintile) & $-0,49 \%$ & $+1,45 \%$ & $-0,51 \%$ \\
\hline Increase in social welfare (euro/person) & +161 & +149 \\
\hline - Only efficiency matters & -93 & +143 & +179 \\
\hline
\end{tabular}

${ }^{a}$ The weight given to richer quintiles is smaller than that given to the poorer quintiles (for example the weight assigned to individuals in quintile 5 is $70 \%$ of the weight given to individuals in quintile 1)

Source: Mayeres et al. (2003)

In Table 6 the welfare effect of each policy reform is presented by means of the percentage change in equivalent income. In the last two rows of the table the total welfare effect is given for two cases. In the first case only economic efficiency

\footnotetext{
${ }^{13}$ see Mayeres \& Proost (2001b, 2003, 2004)

${ }^{14}$ Mayeres (2001)
} 
matters. this means that the total welfare effect is obtained by summing the welfare effects for the individuals in the five income groups. In the second case equity considerations play a role and a weighted sum is made of the welfare effects for the different income groups. A higher weight is assigned to the lower income groups.

When the government pursues a policy that aims to cover the financial costs per mode, the price is set equal to the average financial cost. This entails an increase in the public transport fares and lower taxes on road transport. The total tax revenues from the transport sector fall, which necessitates an increase in the labour tax. In the end everyone looses in this scenario because the transport prices are even less related to the marginal social costs than in the reference situation and because higher taxes need to be imposed on labour. The five income groups are affected differently by this policy reform. For example, the poorest income group mainly suffers from the increase in public transport prices, while the richest income group mainly suffers from the increase in the labour tax.

Table 6 also considers two scenarios with marginal social cost pricing. They lead to extra government revenue. The final effect of marginal social cost pricing therefore depends on the use of this extra revenue. The table presents two possibilities. In the first case the extra revenues are used to reduced the tax on labour by $10 \%$. In the second case the extra revenues are used to increase the social security transfers ${ }^{15}$ by $11 \%$. In both cases the welfare effect is positive for most income groups. If only efficiency matters, the total welfare gain for the economy is the largest when the labour taxes are reduced. However, the income distribution is better when the social security transfers are increased, which explains why this option performs best when equity considerations play a role. These distributional effects can be controlled better by fine-tuning the combination of labour tax reduction and social security transfer increase.

\section{Proposition 15:}

An equitable income distribution is served best by a correct pricing in the transport sector combined with a well-directed use of the revenues to correct for the effects on the poorest income groups.

\footnotetext{
${ }^{15}$ It concerns social security transfers that do not have a direct impact on labour supply, e.g. child allowances etc.
} 


\section{References}

CE, 2002, Returns on Roads: Optimising Road Investments and Use with the 'User Pays Principle'. Delft: CE Delft.

Calthrop, E., S. Proost, 2004, Regulating on Street Parking, Regional Science and Urban Economics, forthcoming.

Calthrop, E., B. De Borger, S. Proost, 2003, Tax Reform for Dirty Intermediate Goods: Theory and Application to the Case of Freight Transport, ETE Working Paper 2003-2. Leuven: Center for Economic Studies, K.U.Leuven.

(www.econ.kuleuven.ac.be/ete/publications)

De Borger, B., 2001, Discrete Choice Models and Optimal Two-part Tariffs in the Presence of Externalities: Optimal Taxation of Cars, Regional Science and Urban Economics 31, 471-504.

De Borger, B., I. Mayeres, 2004, Discrete Choices and Optimal Two-part Tariffs in the Presence of Externalities: An Application to Optimal Taxation of Cars and Public Transport Services, working paper, forthcoming.

De Borger, B., S. Proost (eds.), 2001, Reforming Transport Pricing in the European Union - A Modelling Approach. Cheltenham: Edward Elgar.

ECMT, 2003, Efficient Transport Taxes and Charges. Paris: ECMT. (www.oecd.org/cem).

Mayeres, I. (2001), Equity and Transport Policy Reform, ETE Working Paper 200114. Leuven: Center for Economic Studies, K.U.Leuven.

(www.econ.kuleuven.ac.be/ete/publications)

Mayeres, I., S. Proost, 2001a, Should Diesel Cars in Europe be Discouraged?, Regional Science and Urban Economics 31, 453 - 470.

Mayeres, I., S. Proost, 2001b, Marginal Tax Reform, Externalities and Income Distribution, Journal of Public Economics 79, 343 - 363.

Mayeres, I., S. Proost, 2003, Reforming Transport Pricing: An Economist's Perspective on Equity, Efficiency and Acceptability, in Schade, J. \& B. Schlag, Acceptability of Transport Pricing Strategies, Elsevier. (see also: ETE Working paper 2002-12, www.econ.kuleuven.ac.be/ete/publications)

Mayeres, I., Proost, S., K. Van Dender, 2003, The Impacts of Marginal Social Cost Pricing, in Nash, C. \& B. Matthews, Measuring the Marginal Social Cost of Transport, Elsevier Science, forthcoming.

Mayeres, I., S. Proost, 2004, Achieving Equity through Urban Transport Pricing?, in de Palma, A. \& E. Quinet, Economica, forthcoming. 
Parry, I.W.H. and A. Bento, 2001, Revenue Recycling and the Welfare Effects of Road Pricing, Scandinavian Journal of Economics 103, 645-671.

Proost, S., B. De Borger, 1996, De transportsector in het jaar 2005, Leuvens Economisch Standpunt 1996/85.

Proost, S., K. Van Dender, C. Courcelle, B. De Borger et al., 2002, How Large is the Gap between Present and Efficient Transport Prices in Europe?, Transport Policy 9(1), 41-57.

Proost, S., K. Van Dender, 2001, Welfare Impacts of Alternative Policies to Address Atmospheric Pollution in Urban Road Transport, Regional Science and Urban Economics 31, 383-411.

Proost, S., K. Van Dender, 2004, Marginal Social Cost Pricing for all Transport Modes and the Effects of Modal Budget Constraints, in G. Santos (ed.), Road Pricing: Theory and Evidence, Elsevier, forthcoming.

Van Dender, K. (2003), Transport Taxes with Multiple Trip Purposes, Scandinavian Journal of Economics 105(2), 295-310. 
The Center for Economic Studies (CES) is the research division of the Department of Economics of the Katholieke Universiteit Leuven. The CES research department employs some 100 people. The division Energy, Transport \& Environment (ETE) currently consists of about 15 full time researchers. The general aim of ETE is to apply state of the art economic theory to current policy issues at the Flemish, Belgian and European level. An important asset of ETE is its extensive portfolio of numerical partial and general equilibrium models for the assessment of transport, energy and environmental policies.

\section{ETE WORKING PAPER SERIES 2005}

N²005-04

N²005-03

$N^{\circ} 2005-02$

$N^{\circ} 2005-01$
Mayeres I., Proost S. (2005), Towards better transport pricing and taxation in Belgium

Proost S., Sen A. (2005), URBAN Transport pricing reform with TWO levels of government

Moons E., Saveyn B., Proost S., Hermy M. (2005), Optimal location of new forests in a suburban area

Pepermans G., Willems B. (2005), The potential impact of crossownership in transmission: An application to the Belgian electricity market

\section{ETE WORKING PAPER SERIES 2004}

$N^{\circ} 2004-16$

N²004-15

$N^{\circ} 2004-14$

No2004-13

N²004-12

$N^{\circ} 2004-11$

N²004-10

N²004-09
Franckx L, D'Amato A., Brose I. (2004), Multi Pollutant Yardstick Schemes as Environmental Policy Tools

Rousseau S., Proost S. (2004), The Relative Efficiency of Marketbased Environmental Policy Instruments with Imperfect Compliance

Eyckmans J., Finus M. (2004), An Almost Ideal Sharing Scheme for Coalition Games with Externalities

De Borger B., Mayeres I. (2004), Taxation of car ownership, car use and public transport: insights derived from a discrete choice numerical optimisation model

De Borger B., Proost S. (2004), Vertical and horizontal tax competition in the transport sector

de Palma A., Dunkerley F., Proost S. (2004), Imperfect Competition and Congestion in a City with asymmetric subcenters

Calthrop E., Proost S. (2004), Regulating on-street parking

de Palma A., Proost S. (2004) Imperfect competition and congestion in the City 